\title{
A TEXTBOOK OF TEXT LINGUISTICS FOR MEDICAL STUDENTS
}

\author{
Milieva D. \\ DESO, Medical University - Plovdiv, Bulgaria \\ Reviewed by: Assoc. Prof. V. Tacheva, PhD
}

The Medical Text Linguistics textbook is designed to be used by medical students. The author's multidisciplinary approach uses both medical and textual criteria to structure, build and construe texts in clinical and preclinical medicine.

Text is defined in text linguistics as a communicative occurrence which meets seven criteria of textuality: cohesion (the way in which linguistic items of surface structure are meaningfully interconnected in sequences), coherence (functions through which the concepts and the relations among them are mutually accessible and relevant), intentionality (intention on the part of the sender to produce a cohesive/coherent text aimed at attaining an identifiable goal), acceptability (the receivers' expectation that the text should be coherent/cohesive and of some relevance to them), informativity (the (im)probability or (un)expectedness of a text in the given situation), situationality (the text's relevance to a specific communicative situation) and intertextuality (the ways in which uses of texts depend on the knowledge of other texts, preceding or following).

The texts of the informational type have a markedly expressed cognitive function; they are descriptive texts which convey generally valid knowledge of rules and instructions. When dealing with specialised descriptive texts the emphasis is put on:

1. Analytical interpretation of the category of definition based on operations with the notion content.

2. Informational text structures in the interpretation of scientific information and realisation of language uses through logical assumptions and limitations. This makes it possible to find, identify, systematize and describe informational texts pivots on the one hand, and to structure the texts using logicosemantic schemata, on the other.

Informational texts that clearly belong to the respective specialty are differentiated to fit the content of the description texts. The iconic text is for the specialty of anatomy, the process-describing text - for chemistry, the biology text describes a function, the texts in physics - an argument, in physiology - regulation. These informational texts have a similar compositional scheme (components, characteristic and corollary) with elements that differ by content, function and effect, respectively.

The informational text structures are given in the textbook with their semantic schemes not only in the theoretical texts, but also in the clinical texts, being augmented in the latter with additional elements corresponding to the content of the described pathology in the clinical text and effects.
3. Semiotic invariants in combining figure-based, table-based texts with verbal texts in the electronic publications and multimedia applications. Here, the "informational neutrality" of medical texts is diversified by the sign potential of the texts in the most general sense.

It is possible to categorise all semiotic invariants of a common referent, in which the reference relationship from the referent to the signifier can be :

a) a descriptive variant

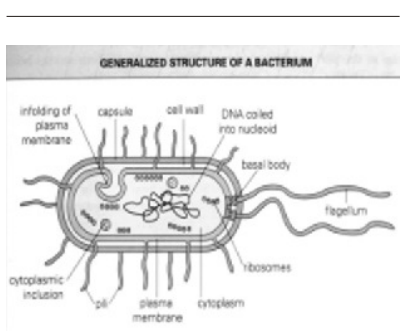

b) a narrative variant

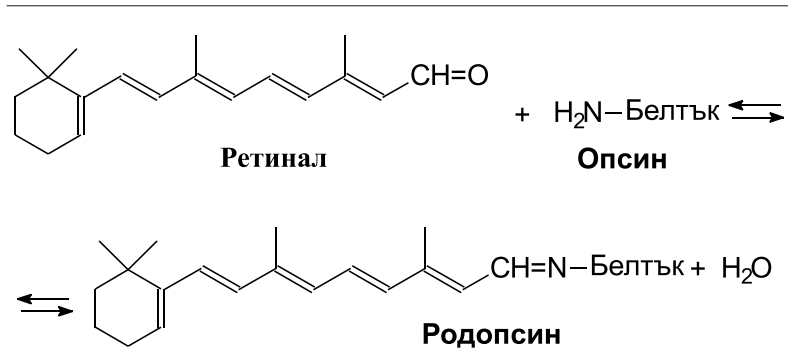

c) an associational variant

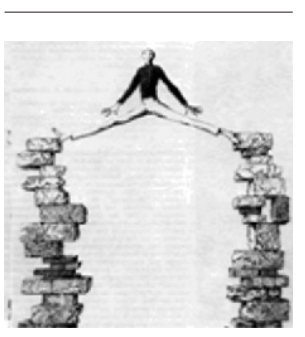

4. Composition of the clinical subjects' texts in the description of morbid processes (disease definition, etiology, pathogenesis, classification, clinical features, differential diagnosis, complications, concomitant diseases, treatment, outcome and prognosis) and meaning relationships between the compositional elements.

The elements of pathology description have constant features which are lexically oppositional (frequent or rare disease, overt or hidden etiology, presence or absence of symptoms). Textually, objective information rejects the al- 
ternative option in which each of the features opposes the other. These relations are either realised in the text or present as hidden information, most often in sentences having contrast substructure with homogeneous parts, that is, we have patterns of contrast (X, but not $\mathrm{Y})$ : the disease is chronic (not acute); coordination (not only $\mathrm{X}$, but also $\mathrm{Y}$, both $\mathrm{X}$ and $\mathrm{Y}$, as much $\mathrm{X}$ as $\mathrm{Y}$ ): a tumour is the more epileptogenic the more benign it is, the slower it increases, the closer it is to the Roland region and the more superficially located it is; joining: The diagnosis is objective and timely at that.

5. Meaning parameters and relationships within the compositional elements in describing a pathological process:

\begin{tabular}{||l|l|c||}
\hline \multicolumn{1}{|c|}{ Elements } & Meaning parameters & $\begin{array}{c}\text { Meaning } \\
\text { relationships }\end{array}$ \\
\hline Etiology & Factors ? Consequence & Cause/effect \\
\hline Pathogenesis & Causes ? Consequence & \\
\hline $\begin{array}{l}\text { Clinical picture } \\
\text { Complications }\end{array}$ & Signs ? Severity/Range & Joining \\
\hline $\begin{array}{l}\text { History of disease, } \\
\text { Physical examination, } \\
\text { Studies }\end{array}$ & $\begin{array}{c}\text { Dialogue? } \\
\text { Changes ? Information } \\
\text { Parameters? }\end{array}$ & Argumentative \\
\hline $\begin{array}{l}\text { Diagnosis, } \\
\text { Differential diagnosis }\end{array}$ & $\begin{array}{c}\text { Interpretation? } \\
\text { Evaluation }\end{array}$ & Resultative \\
\hline Treatment & Measures? Objectives & Prognostic \\
\hline \hline
\end{tabular}

6. Verbal characteristics of the descriptive text: terms and terminological abbreviations; special vocabulary with predominant word-formation categories to form names of abstract notions and pronounced productivity of the word-formation type of adjective + -ост and verbal stem $+\mathrm{e} /$ ние (активност - активиране, поносимост понасяне); use of compound names in which the degree of abstractness of the utterance is reinforced (reliable outcome of the disease); desemantization of the verb-predicate which acquires a semi-formal function (have, contain, possess, consisit of, arise); frequent use of adjective, participles, compound words; use of words which introduce logical context or characterises the objectivity degree of the information (consequently, on the contrary, for this purpose, in the figure, probably, it is believed, undoubtedly); words realising the coordinative and subordinative relations in the sentences. The syntactic constructions that are most frequent are the simple extended sentences; compound coordinative sentences; compound sentences, complex sentences with subordinate adjectival, subordinate conditional, and subordinate causal sentences.

\section{Classification of medical texts:}

\subsection{Descriptive texts:}

Conventional medical texts presenting sufficient number of facts (lecture course, textbooks, a monograph, manuals, reference books)
Experimental medical texts presenting a limited number of facts (scientific communication, articles, studies)

7.2. Event-descriptive texts - the texts which realise meaning relations;

My body and I in taking the history of patients. An event text (taking history of a disease, a physical examination, a test)

You and your diagnosis. A descriptive text (diagnosis, differential diagnosis, complications)

We (patients and the physician) and the methods of treatment. A descriptive text (treatment, outcome, quality of life).

8. Practical aspects of comprehending scientific information through the semantic and syntactic structures included in the texts and understanding of the discrepancies between them.

1. Comprehension, differentiation and interpretation of meanings.

2. Interaction between expressed and nonexpressed information.

3. Synonymous textual options.

4. Orientation about the information centres in the text as well as about the informativity of the text as a whole.

5. Recording, comprehending, summarising, and reproducing scientific information.

\section{REFERENCES}

1. Bogrand P, Dresler V, Yovcheva S. An introductory course in text linguistics. Sofia, 1995

2. Boyadzhiev N, Georgieva K, Damianov I, Iliev Z, Nikolova J, Sarafov D, Trifonov, B. A textbook for human physiology practical seminars for students in pharmaceutics. Helopress, Plovdiv, 2004.

3. Dimitrova, S. Text and context. Nauka I Izkustvo, Sofia, 1984.

4. Dobreva E, Savova I. Text linguistics. Episkop Konstantin Preslavski University Publishing House, Shoumen, 2004.

5. Zagorov M, M.Draganov, M. Murdjeva. Antinuclear antibodies - clinical significance and detection methods. Trakia Journal of Sciences, 2004, 2 (1), 48-57.

6. Lakova M. Principle of constructivism in the grammatical semantics of simple sentences in Bulgarian. Prof. M. Drinov, Sofia, 2002.

7. Lukanov L. Bioorganic chemistry for student of medicine and dentistry. Plovdiv, 2001.

8. Milieva E. Physics for medical students (lecture guidance). Fondacia "Physics, engineering, medicine - XXI”. Plovdiv, 2006.

9. Murdarov V. Modern word-building processes. Sofia, 1983.

10. Murdjeva M, Kirina V. Medical Microbiology. Study Guide for Students in Medicine (Practical exercises). Part 1, Part 2. Plovdiv, ISBN 954-9806-21-9, 1999. 
11. Nitzolova R. About the relationship between grammar and pragmatics. In: Grammar and semantics of the Slavic languages in communication. Sofia, 1994.

12. Piryova B. Brain, Mind and Emotions. Multimedia and computer visualisation studio - NBU, 2003

13. Piryova B. Behavioral medicine. New Bulgarian University, 2000.

14. Sarafian V, M. Vasilevska-Dekova, I1. Vatev, H. Radeva-Kuyamova. Medical biology. A textbook for students of medicine, dentistry and pharmaceutics. MU-Plovdiv, ISBN 954-9549-08-9, 2005.

15. Sivkov S, Novakov S, Daskalova M. Neuroanatomy. Practical textbook. G. Baltadzhieva ed. Plovdiv, 2003.

16. Stefanov V. Logic. A textbook for high school. Nemezida, 2001.

17. Stefanov V. Introductory course in deductive logic. St. Climent Ohridski Universy Publishing House, 2005. 